\title{
Adjacent Segment Pathology After Treatment With Cervical Disc Arthroplasty or Anterior Cervical Discectomy and Fusion, Part 2: Clinical Results at 7-Year Follow-Up
}

\author{
PIERCE D. NUNLEY, MD, EUBULUS J. KERR III, MD, DAVID A. CAVANAUGH, MD, PHILLIP ANDREW \\ UTTER, MD, PETER G. CAMPBELL, MD, RISHI WADHWA, MD, KELLY A. FRANK, MS, KYLE E. \\ MARSHALL, MS, MARCUS B. STONE, PHD \\ Spine Institute of Louisiana, Shreveport, Louisiana
}

\begin{abstract}
Background: Adjacent segment pathology (ASP) following cervical disc arthroplasty (CDA) or anterior cervical discectomy and fusion (ACDF) is identified by imaging (RASP) or clinical symptoms (CASP). Clinical symptoms of CASP have been broadly defined, but subsequent adjacent-level surgeries are clear indicators of CASP. Current literature remains inconsistent in the incidence and potential predictors of CASP. Here, we will evaluate a robust data set for the incidence of CASP resulting in subsequent surgery, attempt to identify factors that might affect CASP, and analyze the association of CASP with patient-reported outcomes (PROS) and RASP.

Methods: Data were prospectively collected during a US Food and Drug Administration randomized, multicenter, investigational device exemption trial comparing CDA (Mobi-C, Zimmer Biomet, Westminster, CO) with ACDF. CASP was defined as any adjacent-level subsequent surgical intervention. Post hoc analyses were conducted on the incidence, time to CASP diagnosis, and relationship of CASP with patient demographics. Longitudinal retrospective case-control analysis was used to assess the correlation of CASP to PROs and radiographic adjacent segment pathology (RASP).

Results: Kaplan-Meier estimates indicated significantly lower probability of CASP over time for 1-level $(P=.002)$ and 2-level $(P=.008) \mathrm{CDA}$ patients. Treatment with ACDF and younger age were associated with higher CASP risk. CDA was more effective than ACDF $(70.5 \% ; 95 \% \mathrm{CI}=45.1,84.2 ; P<.0001)$ at preventing CASP. Case-control analysis indicated increased probability of CASP for patients with grade 3/4 RASP, but the difference was not statistically significant. When we pooled CASP patients, the median grade of RASP at the visit prior to surgery was 1 , with only 6 patients presenting with grade 3/4 RASP.

Conclusions: Patients treated with CDA have a lower incidence of CASP than do patients treated with ACDF, although the mechanism remains unclear. CASP and RASP remain uncorrelated in this large data set, but other predictive variables such as treatment, age, and number of levels should be further investigated.
\end{abstract}

Cervical Spine

Keywords: adjacent segment pathology, cervical disc arthroplasty, anterior cervical discectomy and fusion

\section{INTRODUCTION}

Anterior cervical discectomy and fusion (ACDF) has been the "gold standard" used to treat patients with symptomatic cervical degenerative disc disease. However, long-term follow-up has suggested that $25 \%$ of patients receiving ACDF surgery could develop new disease at an adjacent level within 10 years. ${ }^{1}$ Cervical disc arthroplasty (CDA) was introduced as an alternative surgical treatment to preserve motion at the operative level and was hypothesized to limit degeneration at the adjacent segments. Adjacent segment pathology (ASP) rates for patients treated with $\mathrm{ACDF}$ and CDA have been reported in the form of radiographic and clinical adjacent segment pathology (RASP and CASP, respectively). Part 1 of this publication included results on RASP; here in part 2 we analyze the same patient population for CASP.

CASP is the development of clinical symptoms at the level adjacent to the previously treated level and has been most frequently reported as radicular symptoms. When necessary, subsequent adjacentlevel surgeries are performed to alleviate these symptoms and should be considered as another clear indicator of CASP. According to Jackson et al, ${ }^{1}$ subsequent 5 -year surgeries involving an adja- 
cent level occurred at a significantly lower rate in patients with CDA than in those treated with ACDF at both 1 and 2 levels. This is supported by multiple independent studies comparing ACDF and CDA with various discs. ${ }^{2-6}$

Lee et $\mathrm{al}^{7}$ looked retrospectively at a large series of patients following cervical spine surgery with $\mathrm{ACDF}, \mathrm{CDA}$, posterior decompression, or laminoplasty to determine risk factors of CASP in the form of secondary adjacent surgical intervention and found that women (aged 40-60 years) and smokers were at higher risk of developing CASP. Other authors have found predictors of CASP to be age over 50 years at the time of surgery, developmental canal stenosis, preoperative degeneration of adjacent segments, and postoperative imbalance of sagittal alignment. ${ }^{8,9}$

Whereas RASP and CASP have been widely reported in the literature, the hypothesis that a correlation exists between them remains unproven. Often publications include the results of both RASP and CASP rates within the studied population, but attempted correlation is not reported. ${ }^{10-20}$ The pivotal paper by Hilibrand et $\mathrm{al}^{21}$ was the only exception: The authors found a significant inverse correlation of patients with diagnosed CASP and their degree of radiographic changes. However, this does not account for potential asymptomatic RASP patients, leaving the predictive value of RASP unknown.

Here in part 2 of this publication, we evaluate the incidence of CASP resulting in subsequent surgery, attempt to identify factors that might affect CASP, and analyze the association of CASP with patient reported outcomes (PROS) and RASP.

\section{METHODS}

As previously reported, all data were prospectively collected during a US Food and Drug Administration randomized, multicenter, investigational device exemption (IDE) trial comparing CDA (Mobi-C; Zimmer Biomet, Westminster, CO) with ACDF. Patients were diagnosed with symptomatic degenerative disc disease at 1 or 2 contiguous levels from C3-7. Enrollment in the 1-level arm included 164 patients treated with CDA and 81 patients with ACDF, whereas the 2-level arm included 225 patients treated with CDA and 105 patients with ACDF. Details and overall results of the trial have been reported previously. ${ }^{3,22-26}$
Table 1. Kellgren-Lawrence (K-L) Scale modified for the cervical spine.

K-L Grading Scale:

Grade 0: No degeneration

Grade 1: Minimal anterior osteophytosis

Grade 2: Definite anterior osteophytosis, possible narrowing of disc space

Grade 3: Moderate narrowing of disc space, sclerosis, osteophytosis Grade 4: Severe narrowing of disc space, sclerosis, large osteophytes

\section{Study Design}

Part 2 of this analysis includes a post hoc study of CASP resulting in surgery, as well as its correlation to RASP, for patients treated with CDA and ACDF over 7 years. In the present study, we define CASP as a secondary surgical intervention at a level adjacent to the index surgery. Patient demographics were collected including age, race, gender, height, weight, and body mass index (BMI.) PROs included neck disability index (NDI), visual analog scale (VAS) arm and neck, and the 12-item Short-Form Health Survey mental and physical components (SF-12 MCS and SF-12 PCS).

All available radiographs were analyzed preoperatively and postoperatively at years 1 to 5 and year 7. Radiographic evaluations of RASP were performed by independent radiologists (Medical Metrics Inc, Houston, TX). RASP was evaluated according to the Kellgren-Lawrence (K-L) Scale (Table 1) as modified for cervical spine. ${ }^{27,28}$

A thorough description of the methods and results of RASP in this same population was reported in part 1 of this publication.

\section{Statistical Methods}

\section{Clinical Adjacent Segment Pathology}

CASP was defined as a secondary surgical intervention involving at least 1 adjacent level. Surgical intervention due to trauma was excluded from this analysis. The event time for CASP was defined as the time to first occurrence of an adjacent-level surgery.

Kaplan-Meier estimates of time to CASP were calculated separately for ACDF and CDA groups for the 1-level and 2-level cohorts. The KaplanMeier estimates were compared using the log-rank test. Poisson incidence rates of CASP and corresponding confidence intervals were included on each Kaplan-Meier plot and presented as the number of new cases of CASP as a percentage per patient-year (\%/pt-yr). 


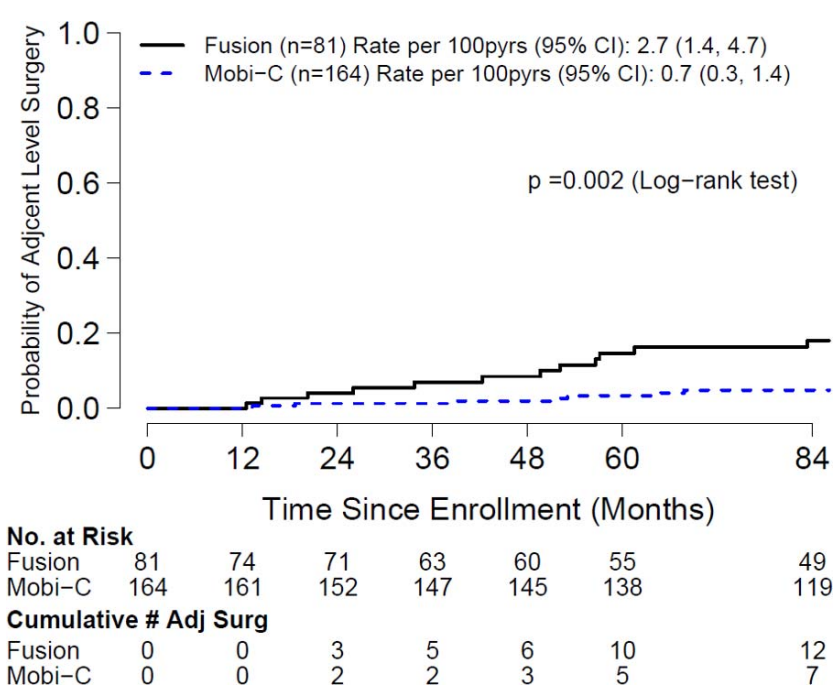

Figure 1. Kaplan Meier: One-level patients time to grade 3/4 clinical adjacent segment pathology (CASP).

Descriptive statistics were used to illustrate whether a relation exists between pooled patients with CASP and their RASP grade and/or change in RASP grade just prior to the secondary surgery. In addition, multivariate Cox proportional hazard models were used to determine whether time to CASP was associated with preoperative patient characteristics and preoperative and postoperative radiographic characteristics. Preoperative covariates included treatment group, levels treated, age, sex, race, BMI, NDI score, and SF-12 MCS and SF-12 PCS scores. Postoperative covariates included C2-7 Cobb angle at 6 weeks, mean flexion-extension range of motion of the index level(s) at 3 months, and mean functional spinal unit (FSU) height of the index level(s) at 6 weeks postoperative. Interactions between treatment and the other covariates were assessed in a serial fashion with bivariate models to determine whether covariates modified the effect of treatment. Estimates of CDA efficacy in preventing CASP were defined as 1 minus the hazard ratio for CDA versus ACDF and presented as a percentage. An efficacy of $0 \%$ indicates no benefit of CDA in preventing CASP as compared with ACDF, whereas an efficacy near $100 \%$ indicates great benefit. ${ }^{29}$

\section{Association of CASP With PROs and RASP: Retrospective Case-Control Analysis}

Using a matched longitudinal retrospective casecontrol analysis, we assessed the correlation of CASP to PRO scores and RASP grade. Cases were matched in a 1:3 ratio using a nearest-neighbor method, matching on sex, levels treated, treatment,

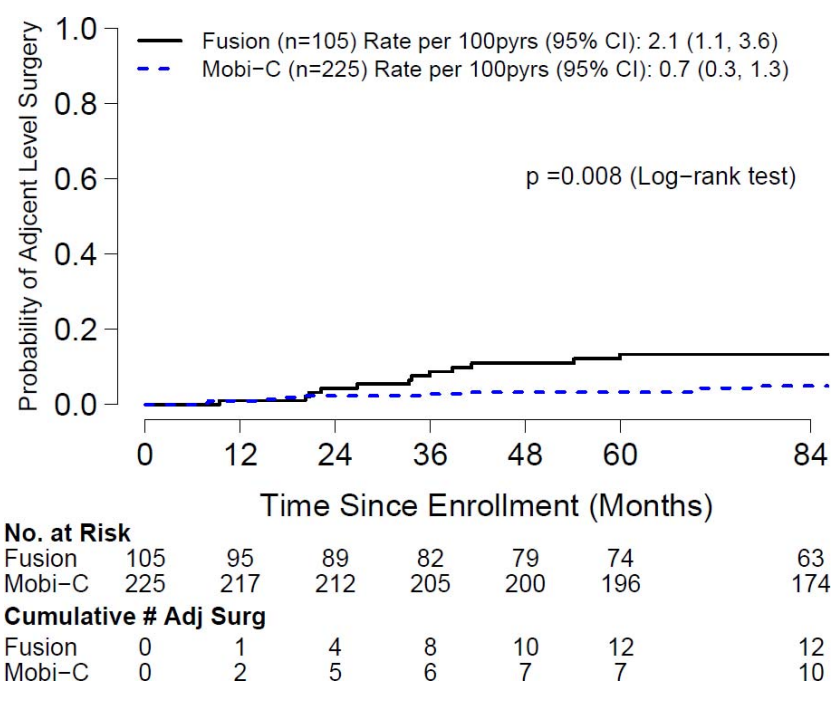

Figure 2. Kaplan Meier: Two-level patients time to grade $3 / 4$ clinical adjacent segment pathology (CASP).

age, and baseline NDI score. Generalized estimating equations models were used to model longitudinal outcomes. Inverse-probability weighting was used to adjust for missing data and censoring. Participant outcomes were censored after having subsequent surgical intervention of any kind.

$P$ values less than .05 were considered statistically significant.

\section{RESULTS}

\section{Clinical Adjacent Segment Pathology}

CASP occurred in 24 patients treated with ACDF, 12 at 1 level and 12 at 2 level, and 17 patients treated with CDA, 7 at 1 level and 10 at 2 level, over a 7-year follow-up.

When pooled, patients with CASP did not have elevated rates of RASP prior to their secondary surgery, with a median grade of 1 , and only 6 patients presented with grade 3/4 RASP. Of the 6 patients with grade $3 / 4$ RASP prior to surgery, 4 did not experience any change in score from baseline, so the RASP was preexisting.

Kaplan-Meier estimates (Figures 1 and 2) show significantly higher probability of CASP over time for patients with ACDF than for patients with CDA for both the 1-level $(P=.002)$ and 2-level $(P=.008)$ cohorts. For the 1-level cohort, the annual incidences of CASP were $2.7(95 \% \mathrm{CI}=1.4,4.7)$ and 0.7 $(95 \% \mathrm{CI}=0.3,1.4)$ per 100 person-years for the ACDF and CDA groups, respectively. For the 2level cohort, the annual incidences of CASP were $2.1(95 \% \mathrm{CI}=1.1,3.6)$ and $0.7(95 \% \mathrm{CI}=0.3,1.3)$ 
per 100 person-years for the ACDF and CDA groups, respectively.

A multivariate Cox model showed significant associations between the risk of CASP and treatment and age (Table 2). Treatment with ACDF and younger age were associated with greater risk of CASP. Patients aged 21 to 34 years at surgery were 10 times more likely to develop CASP than patients aged 50 to 67 years $(P=.0013)$. No other covariates were significantly associated with the risk for CASP. The overall efficacy of CDA preventing CASP compared with ACDF was $70.5 \%(95 \% \mathrm{CI}=45.1$, 84.2; $P<.0001)$. There were no significant effect modifications of treatment by the other covariates (Table 3).

\section{Clinical Adjacent Segment Pathology and Patient- Reported Outcomes}

As we previously reported, the RASP casecontrol analysis showed an increased probability of CASP for patients with grade 3/4 RASP; however, the difference was not statistically significant. In this case-control analysis, CASP patients trended with higher NDI and VAS scores prior to their surgeries than did control patients at the same follow-up time point, but these differences were not statistically significant (Figures 3 and 4). Sensitivity analyses using multivariate models illustrated similar results.

\section{DISCUSSION}

The article by Hilibrand et $\mathrm{al}^{21}$ remains the pivotal publication on CASP following ACDF surgery. The reported rates were an average of $2.9 \%$ annually, with predictions of $25.6 \%$ by 10 years. Hilibrand defined CASP as "the presence of new radicular symptoms or myelopathic symptoms referable to an adjacent degenerated level on two consecutive visits." 21 The definition of CASP has since evolved to include adjacent-level surgeries and PROs. ${ }^{30}$ The varied definitions of CASP make comparisons across the literature difficult. On the basis of our analysis that PROs trend higher with both RASP and CASP with no significance, our focus remained on surgery at the adjacent level as our definition of CASP.

We report a CASP rate for 1 level as $3.7 \%$ CDA versus $13.6 \%$ ADCF $(P<.05)$ and 2 level as $4.4 \%$ CDA versus $11.4 \% \operatorname{ACDF}(P<.05)$. Burkus et $\mathrm{al}^{31}$ reported CASP rates over a 7-year follow-up on the
Table 2. CASP estimated hazard ratio $(H R)$ of CDA versus ACDF, unadjusted and adjusted for baseline and postoperative covariates.

\begin{tabular}{|c|c|c|c|}
\hline Variable & HR & $95 \% \mathrm{CI}$ & $P$ Value $^{\mathrm{a}}$ \\
\hline \multicolumn{4}{|l|}{ Univariate } \\
\hline $\mathrm{ACDF}$ & 1 & & \\
\hline $\mathrm{CDA}$ & 0.29 & $(0.16,0.55)$ & $<.001$ \\
\hline \multicolumn{4}{|l|}{ Multivariate } \\
\hline $\mathrm{ACDF}$ & 1 & & \\
\hline $\mathrm{CDA}$ & 0.23 & $(0.08,0.68)$ & .0073 \\
\hline 1-level & 1 & & \\
\hline 2-level & 1.03 & $(0.54,1.97)$ & .93 \\
\hline \multicolumn{4}{|l|}{ Age, y } \\
\hline $21-34$ & 1 & & \\
\hline $35-49$ & 0.58 & $(0.25,1.35)$ & .20 \\
\hline $50-67$ & 0.1 & $(0.02,0.41)$ & .0013 \\
\hline Female & 1 & & \\
\hline Male & 1.09 & $(0.55,2.19)$ & .80 \\
\hline Non-White & 1 & & \\
\hline White & 0.97 & $(0.29,3.24)$ & .96 \\
\hline $\mathrm{BMI}<30$ & 1 & & \\
\hline $\mathrm{BMI} \geq 30$ & 0.74 & $(0.34,1.58)$ & .43 \\
\hline Preop NDI $<50$ & 1 & & \\
\hline Preop NDI $\geq 50$ & 0.71 & $(0.34,1.47)$ & .36 \\
\hline Preop PCS $<35^{\mathrm{b}}$ & 1 & & \\
\hline Preop PCS $\geq 35$ & 0.71 & $(0.35,1.45)$ & .35 \\
\hline Preop $\mathrm{MCS}<45$ & 1 & & \\
\hline Preop $\mathrm{MCS} \geq 45$ & 0.72 & $(0.37,1.42)$ & .34 \\
\hline Postop Cobb Angle: Neutral ${ }^{\mathrm{c}}$ & 1 & & \\
\hline Postop Cobb Angle: Kyphotic & 0.81 & $(0.27,2.44)$ & .70 \\
\hline Postop Cobb Angle: Lordotic & 0.92 & $(0.44,1.92)$ & .82 \\
\hline Postop $\mathrm{ROM}<2^{\text {od }}$ & 1 & & \\
\hline Postop $2^{\circ} \leq \mathrm{ROM} \leq 8^{\circ}$ & 1.98 & $(0.86,4.59)$ & .11 \\
\hline Postop $\mathrm{ROM}>8^{\circ}$ & 1.52 & $(0.41,5.62)$ & .53 \\
\hline Postop FSU height $<30 \mathrm{~mm}^{\mathrm{e}}$ & 1 & & \\
\hline Postop FSU height $\geq 30 \mathrm{~mm}$ & 0.61 & $(0.3,1.25)$ & .18 \\
\hline
\end{tabular}

Abbreviations: ACDF, anterior cervical discectomy and fusion; BMI, body mass index; CDA, cervical disc arthroplasty; FSU, functional spinal unit; MCS, mental components score; NDI, neck disability index; PCS, physical components score; ROM, range of motion.

${ }^{\text {a }} P$ value compares subgroup $\mathrm{HR}$ to baseline subgroup $(\mathrm{HR}=1)$.

${ }^{\mathrm{b}} \mathrm{PCS}$ and MCS thresholds taken from median baseline scores.

${ }^{\mathrm{c}}$ Postop Cobb angle is $\mathrm{C} 2-7 \mathrm{Cobb}$ angle at 6 weeks postoperative. Kyphotic: angle $<-5^{\circ}$. Neutral: angle between $-5^{\circ}$ and $5^{\circ}$. Lordotic: angle $>5^{\circ}$.

${ }^{\mathrm{d}}$ Postop ROM refers to average ROM at the index level(s) at 3 months postoperative

${ }^{\mathrm{e}}$ Postop FSU height is average FSU height at the index level(s) at 6 weeks postoperative.

Prestige disc of $4.6 \%$ for CDA and $11.9 \%$ for ACDF $(P=.008)$. However, the Kineflex 1-level data indicated no difference between CDA $(7.6 \%)$ and ACDF $(6.1 \%)$ over 24 months. Noteworthy was that $78 \%$ of the Kineflex CASP cases occurred within 12 months of the index surgery. ${ }^{32}$ Secure-C CASP was $1.7 \%(\mathrm{CDA})$ and $1.4 \%(\mathrm{ACDF})$ at 24 months. ${ }^{33}$ A 10-year follow-up of Bryan reported fewer CDA patients with CASP, $9.7 \%$ versus $15.8 \%$ for ACDF, although the difference was not statistically significant $(P=.146){ }^{34}$ Outside the United States, the Discover disc also had similar CASP rates: $2.4 \%(\mathrm{CDA})$ and $2.9 \%(\mathrm{ACDF}){ }^{35}$ Nunley et $\mathrm{al}^{36}$ combined patients receiving 1- or 2level CDA from 4 FDA studies. They reported 5.3\% of CDA patients received a secondary surgery by last follow-up (mean follow-up $=56$ months). ${ }^{36}$ 
Table 3. Estimated incidence of CASP and efficacy of CDA in preventing CASP from months 0 to 84 , by participant characteristics. ${ }^{a}$

\begin{tabular}{|c|c|c|c|c|c|c|c|c|c|c|c|}
\hline \multirow[b]{2}{*}{ Variable } & \multicolumn{4}{|c|}{ ACDF } & \multicolumn{4}{|c|}{ CDA } & \multicolumn{3}{|c|}{ CDA Efficacy } \\
\hline & $\mathbf{n}$ & CASP & Person-years & Rate $^{\text {b }}$ & $\mathbf{n}$ & CASP & Person-years & Rate $^{\text {b }}$ & $\%$ & $(95 \% \mathrm{CI})$ & $P$ Value $^{\mathrm{c}}$ \\
\hline Overall & 186 & 24 & 1018.3 & 2.4 & 389 & 17 & 2443.8 & 0.7 & 70.5 & $(45.1,84.2)$ & $<.0001$ \\
\hline \multicolumn{12}{|l|}{ Levels treated } \\
\hline 1 & 81 & 12 & 442.4 & 2.7 & 164 & 7 & 1019.7 & 0.7 & 81.1 & $(-46.4,97.6)$ & \\
\hline 2 & 105 & 12 & 576.0 & 2.1 & 225 & 10 & 1424.1 & 0.7 & 74.7 & $(35.8,90.1)$ & .65 \\
\hline \multicolumn{12}{|l|}{ Age, y } \\
\hline $21-34$ & 12 & 3 & 60.8 & 4.9 & 48 & 4 & 269.0 & 1.5 & 69.9 & $(-34.6,93.3)$ & \\
\hline $35-49$ & 123 & 20 & 636.6 & 3.1 & 234 & 11 & 1479.2 & 0.7 & 76.4 & $(50.8,88.7)$ & \\
\hline $50-67$ & 51 & 1 & 320.9 & 0.3 & 107 & 2 & 695.7 & 0.3 & 7.5 & $(-92.6,91.6)$ & .54 \\
\hline \multicolumn{12}{|l|}{ Gender } \\
\hline Female & 105 & 17 & 578.0 & 2.9 & 198 & 7 & 1255.0 & 0.6 & 81.0 & $(54.1,92.1)$ & \\
\hline Male & 81 & 7 & 440.4 & 1.6 & 191 & 10 & 1188.8 & 0.8 & 47.4 & $(-38.2,80.0)$ & .12 \\
\hline \multicolumn{12}{|l|}{$\operatorname{Race}^{\mathrm{d}}$} \\
\hline Other & 18 & 2 & 103.4 & 1.9 & 25 & 1 & 148.7 & 0.7 & 65.3 & $(-282.7,96.9)$ & \\
\hline White & 168 & 22 & 914.9 & 2.4 & 364 & 16 & 2295.1 & 0.7 & 71.0 & $(44.8,84.8)$ & .89 \\
\hline \multicolumn{12}{|l|}{ BMI } \\
\hline$<30$ & 134 & 18 & 735.0 & 2.4 & 277 & 14 & 1712.7 & 0.8 & 66.7 & $(32.9,83.4)$ & \\
\hline$\geq 30$ & 52 & 6 & 283.4 & 2.1 & 112 & 3 & 731.1 & 0.4 & 80.6 & $(22.5,95.2)$ & .49 \\
\hline \multicolumn{12}{|l|}{$\mathrm{NDI}$} \\
\hline$<50$ & 69 & 12 & 401.3 & 23.0 & 160 & 6 & 1028.8 & 0.6 & 80.3 & $(47.6,92.6)$ & \\
\hline \multirow{2}{*}{\multicolumn{12}{|c|}{ SF-12 PCS }} \\
\hline & & & & & & & & & & & \\
\hline$<35$ & 120 & 17 & 654.4 & 2.6 & 244 & 10 & 1508.6 & 0.7 & 74.5 & $(44.3,88.3)$ & \\
\hline$\geq 35$ & 66 & 7 & 364.0 & 1.9 & 145 & 7 & 935.2 & 0.7 & 61.1 & $(-11.0,86.4)$ & .53 \\
\hline \multicolumn{12}{|l|}{ SF-12 MCS } \\
\hline$<45$ & 107 & 16 & 574.4 & 2.8 & 222 & 10 & 1386.6 & 0.7 & 74.1 & $(42.9,88.2)$ & \\
\hline$\geq 45$ & 79 & 8 & 444.0 & 1.8 & 167 & 7 & 1057.2 & 0.7 & 63.4 & $(-0.9,86.7)$ & .60 \\
\hline \multicolumn{12}{|c|}{$\mathrm{C} 2-7$ Cobb angle } \\
\hline$\leq 0$ & 36 & 6 & 180.2 & 3.3 & 62 & 3 & 389.6 & 0.8 & 77.3 & $(9.4,94.3)$ & \\
\hline$>0$ & 150 & 18 & 838.1 & 2.1 & 327 & 14 & 2054.2 & 0.7 & 68.2 & $(36.0,84.2)$ & .66 \\
\hline \multicolumn{12}{|l|}{ ROM } \\
\hline$\leq 2^{\circ}$ & 129 & 14 & 732.8 & 1.9 & 5 & 0 & 35.6 & NA & NA & NA & \\
\hline$>2^{\circ}$ & 57 & 10 & 285.5 & 3.5 & 384 & 17 & 2408.2 & 0.7 & 79.8 & $(55.9,90.8)$ & .60 \\
\hline \multicolumn{12}{|l|}{ FSU height } \\
\hline$<30 \mathrm{~mm}$ & 111 & 16 & 596.8 & 2.7 & 156 & 9 & 928.3 & 1.0 & 63.9 & $(18.2,84.0)$ & \\
\hline$\geq 30 \mathrm{~mm}$ & 75 & 8 & 421.5 & 1.9 & 233 & 8 & 1515.5 & 0.5 & 72.2 & $(26.0,89.6)$ & .69 \\
\hline
\end{tabular}

Abbreviations: ACDF, anterior cervical discectomy and fusion; BMI, body mass index; CDA, cervical disc arthroplasty; FSU, functional spinal unit; MCS, mental components score; NA, not applicable; NDI, neck disability index; PCS, physical components score; RASP, radiographic adjacent segment pathology; ROM, range of motion; SF-12, Short-Form Health Survey with 12 items.

${ }^{a}$ Demographic and patient-reported outcomes were taken from preoperative assessments. Radiographic measures are for the first available postoperative assessment

${ }^{\mathrm{b}}$ Rate $=100 \times($ No. with RASP / No. person-yrs)

${ }^{c} P$ values compare CDA efficacy among the groups within a given covariate.

${ }^{\mathrm{d}}$ For race/ethnicity, Asian, Black, Hawaiian/Pacific Islander, Hispanic, Native American/Alaska Native, and multiracial individuals are grouped together as "Other" due to small sample size.

Chang et $\mathrm{al}^{37}$ included the data from these studies and many others for a robust review of 1864 patients treated with CDA and 1572 treated with ACDF. They ${ }^{37}$ reported overall combined CASP of $3.1 \%$ (range, $0.0 \%-7.1 \%$ ) for CDA and $6.0 \%$ (range, $1.0 \%-11.9 \%$ ) for ACDF.

$\mathrm{Xu}$ et $\mathrm{al}^{38}$ published a similar meta-analysis in 2018, although they did not report significant differences between CDA and ACDF. According to the researchers, ${ }^{38} \mathrm{CASP}$ was $2.4 \%(\mathrm{CDA})$ and $4.5 \%$ ACDF with an odds ratio (OR) of 0.97 . A third meta-analysis confirmed significant differences in favor of $\mathrm{CDA}(\mathrm{OR}=0.43,95 \% \mathrm{CI}=0.29,0.64 ; P$ $<.0001)^{39}$

Our analysis indicated the risk of CASP was significantly correlated to treatment and age, with $\mathrm{ACDF}$ and younger patients at higher risk. Other analyses $^{40-46}$ found potential CASP risk factors included preexisting disease, age less than 60 years, level-treated osteopenia, lumbar degenerative disc disease, disruption of the adjacent segment (including increased motion after surgery), and sagittal balance. Younger age as a risk factor is supported by other trials and is believed to be related to longer time, allowing for natural progression of disease. ${ }^{40}$ Boden et $\mathrm{al}^{47}$ also supported natural progression of the disease, reporting that $19 \%$ of asymptomatic patients had an abnormality noted on MRI. This percentage increased to $28 \%$ for patients over 40 years old. $^{47}$

Whereas our analysis did not indicate postoperative range of motion to be an independent risk factor, earlier disruption to the adjacent segment from increased range of motion should still be 


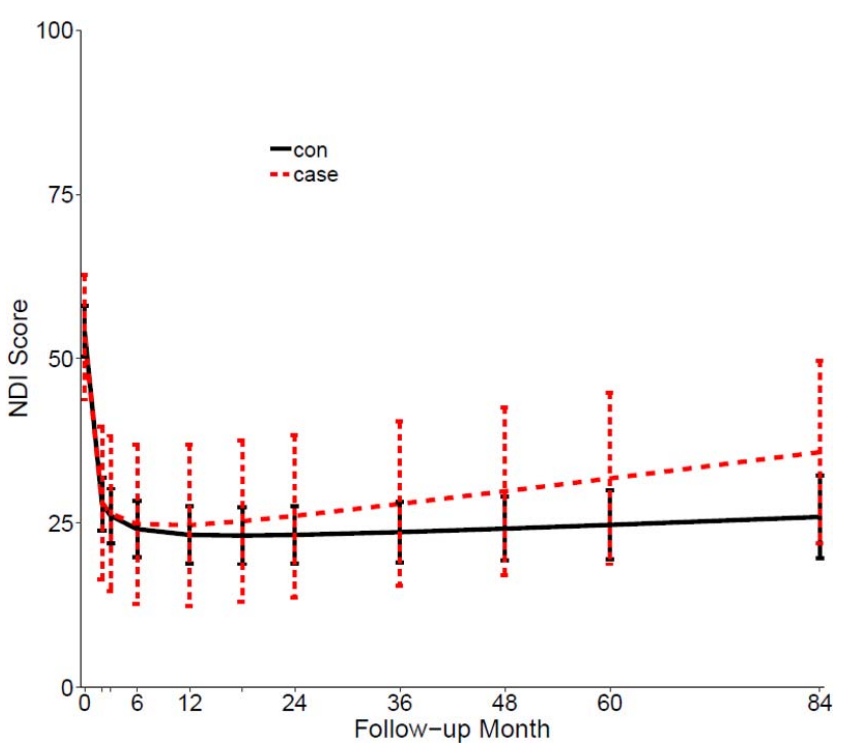

Figure 3. Case-control analysis: longitudinal neck disability index (NDI) score by case-control status.

considered. It is also possible that in our models the effect of range of motion was largely captured in the effect of treatment modality.

Many hypothesize that the increased length of construct or number of levels treated would increase the risk of CASP. Literature ${ }^{48}$ supports our findings that the risk of CASP is not correlated to number of levels treated for CDA or ACDF. However, it is important to understand that CASP rates could be affected by conservative index treatment. Of the CASP patients in our analysis, 4 had a RASP grade of $3 / 4$ at the time of index surgery, potentially indicating that the index surgery was conservative. The Kineflex trial reported $78 \%$ of the CDA CASP occurred in the first 12 months following index treatment. ${ }^{32}$ The early timing of these adjacent-level surgeries leads us to question whether the adjacentlevel pathology was present at the initial surgery. Lundine et $\mathrm{al}^{45}$ reviewed preoperative MRIs of patients who underwent 1- and 2-level ACDF. They found evidence of preoperative disc degeneration at the nonoperative levels, with the degeneration at adjacent levels being significantly more advanced. ${ }^{45}$

As early as 1990 , Boden et $\mathrm{al}^{47}$ reported that imaging alone is not a good predictor of disease, given that $19 \%$ of asymptomatic patients presented with abnormalities identified on imaging. Surgeons are in a delicate position, needing to evaluate radiographs and correlated symptoms to ensure they are treating all the symptomatic levels while not overtreating.

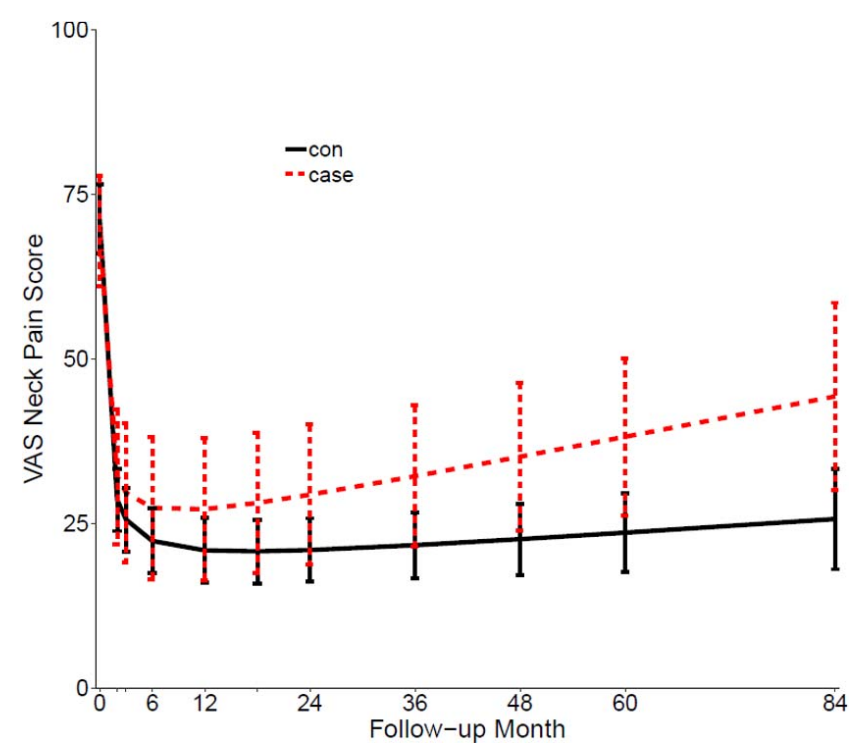

Figure 4. Case-control analysis: longitudinal visual analog scale (VAS) score by case-control status.

This analysis contains limitations because it is a post hoc analysis of a prospective study, not a prospectively planned analysis of CASP. Radiographic variables were fixed at early time points to determine whether early radiographic measurements could predict CASP. However, many of these radiographic characteristics are dynamic, and we did not capture their changes with time in our analyses. Prospective analyses powered to capture differences in RASP and CASP should be considered.

\section{CONCLUSION}

The data remain consistent that CDA provides protection against CASP, with both lower incidence of symptomatic radiculopathy and lower risk of secondary surgery. A correlation of CASP with RASP remains unproven, and other predictive variables, such as treatment, age, and number of levels, should be considered and investigated further. Although the mechanism remains unclear, our study and multiple other publications indicate that the risk of CASP is increased in patients treated with ACDF rather than CDA. ${ }^{37,38,49}$

\section{REFERENCES}

1. Jackson RJ, Davis RJ, Hoffman GA, et al. Subsequent surgery rates after cervical total disc replacement using a Mobi$\mathrm{C}$ cervical disc prosthesis versus anterior cervical discectomy and fusion: a prospective randomized clinical trial with 5-year follow-up. J Neurosurg Spine. 2016;24(5):734-745.

2. Lanman TH, Burkus JK, Dryer RG, Gornet MF, 
McConnell J, Hodges SD. Long-term clinical and radiographic outcomes of the Prestige LP artificial cervical disc replacement at 2 levels: results from a prospective randomized controlled clinical trial. J Neurosurg Spine. 2017;27(1):7-19.

3. Radcliff K, Davis RJ, Hisey MS, et al. Long-term evaluation of cervical disc arthroplasty with the Mobi-C(C) cervical disc: a randomized, prospective, multicenter clinical trial with seven-year follow-up. Int J Spine Surg. 2017;11(4):31.

4. Burkus JK, Haid RW, Traynelis VC, Mummaneni PV. Long-term clinical and radiographic outcomes of cervical disc replacement with the Prestige disc: results from a prospective randomized controlled clinical trial. J Neurosurg Spine. 2010;13(3):308-318.

5. Heller J, Sasso R, Papadopoulos S, et al. Comparison of Bryan cervical disc arthroplasty with anterior cervical decompression and fusion : clinical and radiographic results of a randomized, controlled, clinical trial. Spine (Phila Pa 1976). 2009;34(2):101-107.

6. Mummaneni PV, Burkus JK, Haid RW, Traynelis VC, Zdeblick TA. Clinical and radiographic analysis of cervical disc arthroplasty compared with allograft fusion: a randomized controlled clinical trial. J Neurosurg Spine. 2007;6(3):198-209.

7. Lee JC, Lee SH, Peters C, Riew KD. Risk-factor analysis of adjacent-segment pathology requiring surgery following anterior, posterior, fusion, and nonfusion cervical spine operations: survivorship analysis of 1358 patients. J Bone Joint Surg Am. 2014;96(21):1761-1767.

8. Wang F, Hou HT, Wang P, Zhang JT, Shen Y. Symptomatic adjacent segment disease after single-lever anterior cervical discectomy and fusion: incidence and risk factors. Medicine (Baltimore). 2017;96(47):e8663.

9. Kong L, Sun C, Kou N, et al. Risk factors associated with clinical adjacent segment pathology following multi-level cervical fusion surgery. Medicine (Baltimore). 2018;97(48):e13480.

10. Goffin J, Geusens E, Vantomme N, et al. Long-term follow-up after interbody fusion of the cervical spine. $J$ Spinal Disord Tech. 2004;17(2):79-85.

11. Gore DR, Sepic SB. Anterior discectomy and fusion for painful cervical disc disease. A report of 50 patients with an average follow-up of 21 years. Spine (Phila Pa 1976). 1998;23(19):2047-2051.

12. Song KJ, Choi BW, Jeon TS, Lee KB, Chang $\mathrm{H}$. Adjacent segment degenerative disease: is it due to disease progression or a fusion-associated phenomenon? Comparison between segments adjacent to the fused and non-fused segments. Eur Spine J. 2011;20(11):1940-1945.

13. Ishihara H, Kanamori M, Kawaguchi Y, Nakamura H, Kimura T. Adjacent segment disease after anterior cervical interbody fusion. Spine J. 2004;4(6):624-628.

14. Marotta N, Landi A, Tarantino R, Mancarella C, Ruggeri A, Delfini R. Five-year outcome of stand-alone fusion using carbon cages in cervical disc arthrosis. Eur Spine J. 2011;20 (suppl 1):S8-S12.

15. Yue WM, Brodner W, Highland TR. Long-term results after anterior cervical discectomy and fusion with allograft and plating: a 5- to 11-year radiologic and clinical follow-up study. Spine (Phila Pa 1976). 2005;30(19):2138-2144.

16. Bolesta MJ, Rechtine GR, Chrin AM. One- and twolevel anterior cervical discectomy and fusion: the effect of plate fixation. Spine J. 2002;2(3):197-203.
17. Komura S, Miyamoto K, Hosoe H, Iinuma N, Shimizu $\mathrm{K}$. Lower incidence of adjacent segment degeneration after anterior cervical fusion found with those fusing C5-6 and C6-7 than those leaving C5-6 or C6-7 as an adjacent level. $J$ Spinal Disord Tech. 2012;25(1):23-29.

18. Greiner-Perth R, Allam Y, El-Saghir H, Röhl F, Franke J, Böhm H. Analysis of reoperations after surgical treatment of degenerative cervical spine disorders: a report on 900 cases. Cent Eur Neurosurg. 2009;70(1):3-8.

19. Katsuura A, Hukuda S, Saruhashi Y, Mori K. Kyphotic malalignment after anterior cervical fusion is one of the factors promoting the degenerative process in adjacent intervertebral levels. Eur Spine J. 2001;10(4):320-324.

20. Matsumoto M, Okada E, Ichihara D, et al. Anterior cervical decompression and fusion accelerates adjacent segment degeneration: comparison with asymptomatic volunteers in a ten-year magnetic resonance imaging follow-up study. Spine (Phila Pa 1976). 2010;35(1):36-43.

21. Hilibrand AS, Carlson GD, Palumbo MA, Jones PK, Bohlman HH. Radiculopathy and myelopathy at segments adjacent to the site of a previous anterior cervical arthrodesis. $J$ Bone Joint Surg Am. 1999;81(4):519-528.

22. Davis RJ, Kim KD, Hisey MS, et al. Cervical total disc replacement with the Mobi-C cervical artificial disc compared with anterior discectomy and fusion for treatment of 2-level symptomatic degenerative disc disease: a prospective, randomized, controlled multicenter clinical trial: clinical article. $J$ Neurosurg Spine. 2013;19(5):532-545.

23. Davis RJ, Nunley PD, Kim KD, et al. Two-level total disc replacement with Mobi-C cervical artificial disc versus anterior discectomy and fusion: a prospective, randomized, controlled multicenter clinical trial with 4-year follow-up results. J Neurosurg Spine. 2015;22(1):15-25.

24. Hisey MS, Bae HW, Davis R, et al. Multi-center, prospective, randomized, controlled investigational device exemption clinical trial comparing Mobi-C cervical artificial disc to anterior discectomy and fusion in the treatment of symptomatic degenerative disc disease in the cervical spine. Int J Spine Surg. 2014;8:7.

25. Hisey MS, Bae HW, Davis RJ, et al. Prospective, randomized comparison of cervical total disk replacement versus anterior cervical fusion: results at 48 months follow-up. $J$ Spinal Disord Tech. 2015;28(4):E237-E243.

26. Hisey MS, Zigler JE, Jackson R, et al. Prospective, randomized comparison of one-level Mobi-C cervical total disc replacement vs anterior cervical discectomy and fusion: results at 5-year follow-up. Int J Spine Surg. 2016;10:10.

27. Kellgren JH, Lawrence JS. Radiological assessment of osteo-arthrosis. Ann Rheum Dis. 1957;16(4):494-502.

28. Kettler A, Wilke HJ. Review of existing grading systems for cervical or lumbar disc and facet joint degeneration. Eur Spine J. 2006;15(6):705-718.

29. Sashegyi A, Ferry D. On the interpretation of the hazard ratio and communication of survival benefit. Oncologist. 2017;22(4):484-486.

30. Kaye ID, Hilibrand AS. Adjacent level disease-background and update based on disc replacement data. Curr Rev Musculoskelet Med. 2017;10(2):147-152.

31. Burkus JK, Traynelis VC, Haid RW, Mummaneni PV. Clinical and radiographic analysis of an artificial cervical disc: 7-year follow-up from the Prestige prospective randomized 
controlled clinical trial: clinical article. J Neurosurg Spine. 2014;21(4):516-528.

32. Coric D, Nunley PD, Guyer RD, et al. Prospective, randomized, multicenter study of cervical arthroplasty: 269 patients from the Kineflex $\mid \mathrm{C}$ artificial disc investigational device exemption study with a minimum 2-year follow-up: clinical article. J Neurosurg Spine. 2011;15(4):348-358.

33. Vaccaro A, Beutler W, Peppelman W, et al. Clinical outcomes with selectively constrained Secure-C cervical disc arthroplasty: two-year results from a prospective, randomized, controlled, multicenter investigational device exemption study. Spine (Phila Pa 1976). 2013;38(26):2227-2239.

34. Ghobrial GM, Lavelle WF, Florman JE, Riew KD, Levi AD. Symptomatic adjacent level disease requiring surgery: analysis of 10-year results from a prospective, randomized, clinical trial comparing cervical disc arthroplasty to anterior cervical fusion. Neurosurgery. 2019;84(2):347-354.

35. Skeppholm M, Lindgren L, Henriques T, Vavruch L, Löfgren H, Olerud C. The Discover artificial disc replacement versus fusion in cervical radiculopathy - a randomized controlled outcome trial with 2-year follow-up. Spine $J$. 2015;15(6):1284-1294.

36. Nunley PD, Jawahar A, Cavanaugh DA, Gordon CR, Kerr EJ, Utter PA. Symptomatic adjacent segment disease after cervical total disc replacement: re-examining the clinical and radiological evidence with established criteria. Spine $J$. 2013;13(1):5-12.

37. Chang KE, Pham MH, Hsieh PC. Adjacent segment disease requiring reoperation in cervical total disc arthroplasty: a literature review and update. J Clin Neurosci. 2017;37:20-24.

38. Xu S, Liang Y, Zhu Z, Qian Y, Liu H. Adjacent segment degeneration or disease after cervical total disc replacement: a meta-analysis of randomized controlled trials. J Orthop Surg Res. 2018;13(1):244-253.

39. Luo J, Wang H, Peng J, Deng Z, Zhang Z, Liu S, et al. Rate of adjacent segment degeneration of cervical disc arthroplasty versus fusion meta-analysis of randomized controlled trials. World Neurosurg. 2018;113:225-231.

40. Helgeson MD, Bevevino AJ, Hilibrand AS. Update on the evidence for adjacent segment degeneration and disease. Spine J. 2013;13(3):342-351.

41. Chang UK, Kim DH, Lee MC, Willenberg R, Kim SH, Lim J. Changes in adjacent-level disc pressure and facet joint force after cervical arthroplasty compared with cervical discectomy and fusion. J Neurosurg Spine. 2007;7(1):33-39.

42. Finn MA, Brodke DS, Daubs M, Patel A, Bachus KN. Local and global subaxial cervical spine biomechanics after single-level fusion or cervical arthroplasty. Eur Spine J. 2009;18(10):1520-1527.

43. Nassr A, Lee JY, Bashir RS, et al. Does incorrect level needle localization during anterior cervical discectomy and fusion lead to accelerated disc degeneration? Spine (Phila Pa 1976). 2009;34(2):189-192.
44. Anakwenze OA, Auerbach JD, Milby AH, Lonner BS, Balderston RA. Sagittal cervical alignment after cervical disc arthroplasty and anterior cervical discectomy and fusion: results of a prospective, randomized, controlled trial. Spine (Phila Pa 1976). 2009;34(19):2001-2007.

45. Lundine KM, Davis G, Rogers M, Staples M, Quan G. Prevalence of adjacent segment disc degeneration in patients undergoing anterior cervical discectomy and fusion based on pre-operative MRI findings. J Clin Neurosci. 2014;21(1):82-85.

46. Kelly MP, Mok JM, Frisch RF, Tay BK. Adjacent segment motion after anterior cervical discectomy and fusion versus ProDisc-c cervical total disk arthroplasty: analysis from a randomized, controlled trial. Spine (Phila Pa 1976). 2011;36(15):1171-1179.

47. Boden SD, McCowin PR, Davis DO, Dina TS, Mark AS, Wiesel S. Abnormal magnetic-resonance scans of the cervical spine in asymptomatic subjects. A prospective investigation. J Bone Joint Surg Am. 1990;72(8):1178-1184.

48. Bydon M, Xu R, Macki M, et al. Adjacent segment disease after anterior cervical discectomy and fusion in a large series. Neurosurgery. 2014;74(2):139-146, discussion 146.

49. Carrier CS, Bono CM, Lebl DR. Evidence-based analysis of adjacent segment degeneration and disease after ACDF: a systematic review. Spine J. 2013;13:1370-1378.

Disclosures and COI: Pierce Nunley receives royalties from $\mathrm{K} 2 \mathrm{M}$, Zimmer Biomet, Camber Spine, and Integrity Spine; is on the speakers bureau for K2M, Zimmer Biomet, Spineology, and Camber Spine; and is a paid consultant for K2M, Zimmer Biomet, Spineology, Vertiflex, Camber Spine, Integrity Spine, and Centinel Spine. He has stock or stock options in Paradigm, Spineology, and Camber Spine. Peter Campbell is a paid consultant for $4 \mathrm{Web}$ and Titan Spine. The other authors received no funding for this study and report no conflicts of interest.

Corresponding Author: Pierce D. Nunley, 1500 Line Ave, Suite 200, Shreveport, LA 71101. Phone: (318) 629-5555; Fax: (318) 629-5556; Email: pnunley@louisianaspine.org.

Published 30 June 2020

This manuscript is generously published free of charge by ISASS, the International Society for the Advancement of Spine Surgery. Copyright (C) 2020 ISASS. To see more or order reprints or permissions, see http://ijssurgery.com. 